\title{
Exercise Is Medicine: Primary Care Counseling on Aerobic Fitness and Muscle Strengthening
}

\author{
Casey Crump, MD, PhD, Kristina Sundquist, MD, PhD, Jan Sundquist, MD, PhD, and \\ Marilyn A. Winkleby, $P h D$
}

Patient counseling on physical fitness remains underutilized in primary care, despite its clinical and cost effectiveness. Most counseling interventions have focused on aerobic activity and neglected another vital component of physical fitness, muscle strengthening, which has recently been shown to be independently protective against cardiometabolic diseases and premature mortality. This article reviews the latest scientific evidence and makes recommendations toward a more comprehensive approach for promoting physical fitness in primary care. Given the high prevalence and wide-ranging health impacts of physical inactivity, counseling on physical fitness should be a standard part of wellness promotion and disease prevention and treatment for all patients. Interventions that include muscle strengthening will have a significantly greater impact on health outcomes than those focused on aerobic fitness alone. Counseling to promote both aerobic fitness and muscle strengthening is indicated for all patients, irrespective of body weight, and should begin early in life and continue across the life course. ( $\mathrm{J}$ Am Board Fam Med 2019;32:103-107.)

Keywords: Counseling, Exercise, Physical Fitness, Premature Mortality, Primary Health Care

In 2007, the "Exercise Is Medicine" initiative was launched by the American College of Sports Medicine and American Medical Association with the goal of making "physical activity assessment and exercise prescription a standard part of the disease prevention and treatment paradigm for all pa-

This article was externally peer reviewed.

Submitted 24 July 2018; revised 25 August 2018; accepted 3 October 2018.

From Departments of Family Medicine and Community Health and of Population Health Science and Policy, Icahn School of Medicine at Mount Sinai, New York, NY (CC, KS, JS); Center for Primary Health Care Research, Lund University, Malmö, Sweden (KS, JS); Stanford Prevention Research Center, Stanford University, Stanford, CA (MAW).

Funding: This work was supported by the National Heart, Lung, and Blood Institute at the National Institutes of Health (R01 HL116381); the Swedish Research Council; and ALF project grant, Region Skåne/Lund University, Sweden. The funding agencies had no role in the design and conduct of the study; in the collection, analysis, and interpretation of the data; or in the preparation, review, or approval of the manuscript.

Conflict of interest: none declared.

Corresponding author: Casey Crump, MD, $\mathrm{PhD}$, Departments of Family Medicine and Community Health and of Population Health Science and Policy, Icahn School of Medicine at Mount Sinai, One Gustave L. Levy Place, Box 1077, New York, NY 10029 (E-mail: casey.crump@mssm.edu). tients." ${ }^{1}$ Since then, several large health care organizations have adopted physical activity as a "vital sign" that is routinely assessed and documented in the electronic health record. ${ }^{2-4}$ Despite these emerging efforts, patient counseling on physical fitness continues to be underutilized in primary care. ${ }^{5,6}$ In US national sample surveys, only 1 in 3 adults report having received counseling on physical fitness or exercise from their physician in the past year, with similar rates among children., Certain subgroups, including racial/ethnic minorities and the elderly, are even less likely to receive such counseling. ${ }^{9}$ Furthermore, most counseling interventions have focused on aerobic activity ${ }^{2-4}$ and neglected another vital component of physical fitness, namely muscle strengthening, which has recently been shown to be independently protective against cardiometabolic diseases and premature death. ${ }^{10-16}$ This article reviews the latest scientific evidence and makes recommendations toward a more comprehensive approach for promoting physical fitness in primary care.

Prior research indicates that physical inactivity increases cardiovascular disease (CVD) risks and mortality by a similar magnitude as other well- 
established risk factors, such as smoking and obesity. ${ }^{17}$ In addition, physical inactivity is linked with a broad range of other diseases, including diabetes, cancer, musculoskeletal disorders, and depression, affecting nearly every organ system. ${ }^{17}$ Its wideranging effects are especially important in highly sedentary modern societies like the United States, where physical inactivity is the most common modifiable risk factor for chronic diseases. ${ }^{18,19}$ Given the high prevalence and extensive health impacts of physical inactivity, counseling on physical fitness and exercise should be a standard part of wellness promotion and disease prevention and treatment for all primary care patients.

New scientific evidence underscores the importance of muscle strengthening in addition to aerobic (cardiorespiratory) fitness. The earliest uses of physical activity as a vital sign in electronic health records have focused only on aerobic activity. ${ }^{2-4}$ However, muscle strength is another essential component of physical fitness that has been shown to have independent long-term effects on disease risks and mortality. Recent large national cohort studies in Sweden demonstrate that in addition to low aerobic fitness, low muscle strength also is a strong risk factor for the development of type 2 diabetes, ${ }^{10}$ heart failure, ${ }^{13}$ stroke,${ }^{14}$ and premature mortality, ${ }^{15}$ independent of aerobic fitness and body mass index (BMI). Table 1 summarizes these findings for CVD-related outcomes and mortality in the largest cohort to date $\left(\sim 1.5\right.$ million men).$^{13}$ Moreover, aerobic fitness and muscle strength were found to have synergistic effects on these outcomes, that is, their combined effect exceeded the sum or product of their separate effects. ${ }^{13-15}$ Men in the highest compared with lowest tertile of muscle strength had a $10 \%$ to $20 \%$ reduced risk of type 2 diabetes and a $10 \%$ to $40 \%$ reduced risk of premature death, irrespective of aerobic fitness level. ${ }^{10,15}$ These findings suggest that patient counseling interventions that include muscle strengthening will have a significantly greater impact on disease outcomes than those focused on aerobic fitness alone.

The benefits of physical fitness counseling extend to people of all body weights and across the life course. Large cohort studies have shown that both high aerobic fitness and high muscle strength are protective against long-term CVD risks and mortality irrespective of body weight or BMI. ${ }^{10-15}$ They are beneficial even in persons who have a normal weight, and regardless of weight loss in those who are overweight or obese. ${ }^{20}$ These relationships are potentially explained by the preferential effects of aerobic or muscle-strengthening exercise on reducing visceral (intra-abdominal) adiposity, which is highly correlated with inflammatory biomarkers and insulin resistance but has less influence on BMI than subcutaneous fat. ${ }^{21-24}$ Both aerobic fitness and muscle strengthening also have beneficial health effects at all ages, from childhood through older adulthood. ${ }^{10-15,20,25}$ Individually tailored counseling to promote physical fitness is, therefore, indicated for all patients, even those

Table 1. Associations between Aerobic Fitness, Muscle Strength, or Body Mass Index in 1.5 Million 18-Year-01d Men and Subsequent Risk of Cardiovascular Disease-Related Outcomes and Mortality in Adulthood, Sweden, 1969 to $2012^{*}$

\begin{tabular}{|c|c|c|c|c|c|c|c|c|c|}
\hline \multirow[b]{2}{*}{ Outcome } & \multicolumn{3}{|c|}{$\begin{array}{l}\text { Aerobic Fitness (trend test per } \\
100 \text { Watts) }\end{array}$} & \multicolumn{3}{|c|}{$\begin{array}{l}\text { Muscle Strength (trend test } \\
\text { per } 1000 \text { Newtons) }\end{array}$} & \multicolumn{3}{|c|}{ BMI (trend test per 1 unit) } \\
\hline & $\mathrm{HR}^{\dagger}$ & $95 \% \mathrm{CI}$ & $P$ & $\mathrm{HR}^{\dagger}$ & $95 \% \mathrm{CI}$ & $P$ & $\mathrm{HR}^{\dagger}$ & $95 \% \mathrm{CI}$ & $P$ \\
\hline Hypertension & 0.70 & $0.69-0.71$ & $<.001$ & 1.02 & $1.00-1.04$ & .02 & 1.08 & $1.07-1.09$ & $<.001$ \\
\hline Type 2 diabetes & 0.66 & $0.64-0.67$ & $<.001$ & 0.84 & $0.81-0.87$ & $<.001$ & 1.06 & $1.06-1.07$ & $<.001$ \\
\hline Ischemic heart disease & 0.64 & $0.63-0.66$ & $<.001$ & 1.01 & $0.98-1.05$ & .37 & 1.07 & $1.06-1.07$ & $<.001$ \\
\hline Stroke & 0.61 & $0.59-0.64$ & $<.001$ & 0.87 & $0.83-0.91$ & $<.001$ & 1.05 & $1.04-1.06$ & $<.001$ \\
\hline Heart failure & 0.51 & $0.48-0.54$ & $<.001$ & 0.72 & $0.67-0.77$ & $<.001$ & 1.08 & $1.08-1.09$ & $<.001$ \\
\hline Atrial fibrillation & 0.99 & $0.95-1.02$ & .41 & 0.94 & $0.90-0.98$ & .006 & 1.05 & $1.05-1.06$ & $<.001$ \\
\hline CVD mortality & 0.46 & $0.44-0.49$ & $<.001$ & 0.58 & $0.55-0.62$ & $<.001$ & 1.08 & $1.07-1.09$ & $<.001$ \\
\hline All-cause mortality & 0.55 & $0.54-0.57$ & $<.001$ & 0.73 & $0.71-0.75$ & $<.001$ & 1.03 & $1.02-1.04$ & $<.001$ \\
\hline
\end{tabular}

*Crump C, et al. Heart. 2017;103:1780-1787.

${ }^{\dagger}$ Adjusted for age, calendar year, aerobic fitness, muscle strength, BMI, education, neighborhood socioeconomic status, and family history of the respective condition (or family history of any CVD in analyses of mortality).

BMI, body mass index; CVD, cardiovascular disease; HR, hazard ratio; CI, confidence interval. 
who are at a normal weight, and should begin early in life and continue across the life course.

Patient counseling in the primary care setting is one of the most feasible and effective means of promoting physical fitness in the health care system. Brief ( $<5$ minute) counseling during a primary care visit has been shown to be clinically effective and cost-effective for improving physical activity, analogous to smoking cessation counseling. ${ }^{26}$ For example, a meta-analysis of 15 randomized controlled trials with 8745 sedentary adults found that patient counseling in primary care resulted in significantly higher odds of achieving target physical activity levels after 12 months, compared with patients who received usual care (odds ratio, 1.42; 95\% confidence interval, 1.17-1.73). ${ }^{27}$ Another meta-analysis of 21 randomized controlled trials with 10,519 healthy adults reported that patient counseling in primary care settings was associated with significantly longer duration of physical activity (and a mean increase of $>2,000$ pedometer steps/day) after 12 months. ${ }^{28}$ Other studies have further shown that patient counseling on physical activity improved cardiorespiratory fitness, ${ }^{29}$ reduced CVD risks, ${ }^{30}$ and did not disrupt or increase the length of clinic visits. ${ }^{31}$ Table 2 provides strategies and talking points for integrating physical fitness counseling into primary care visits. Such counseling is both cost- and time-efficient and will likely enhance health outcomes.

In addition to primary care counseling, broader community interventions are also essential for enhancing physical fitness in the general population. Recent population-based findings for both aerobic fitness and muscle strength ${ }^{10-15}$ further corrobo- rate existing World Health Organization guidelines for physical activity (shown in Table 2). ${ }^{32}$ Interventions to promote these goals are particularly needed in underserved and high-risk subgroups, including racial/ethnic minorities, older adults, and rural populations. ${ }^{7-9}$ Given recent federal and state funding cuts, there is a pressing need for more equitable provision of physical education for children and youth in under-resourced schools. ${ }^{33}$ Community-based interventions, including walking groups, exercise classes, and health coaching, have been found to significantly enhance physical activity among older adults, particularly when tailored to the local context. ${ }^{34}$ The built environment and community walkability are also critical for enhancing physical activity and should be a priority for public policy. ${ }^{35}$ Further research will be needed to elucidate what community-based interventions are most effective and how best to tailor them for different population subgroups and communities.

A substantial body of research has underscored a pressing need to promote physical fitness more proactively and consistently throughout the health care system. ${ }^{5}$ Physical exercise is an essential firstline treatment for most chronic diseases ${ }^{4}$ and plays a key role in reducing health care expenditures. ${ }^{36}$ Prescribed interventions should include not only weight control and aerobic fitness but also muscle strengthening, which is independently linked with lower disease risks ${ }^{10-14}$ and improved outcomes and longevity. ${ }^{15,37}$ Better dissemination of new evidence on the beneficial effects of both aerobic fitness and muscle strength is needed among physicians, patients, the general public, and policymak-

\section{Table 2. Strategies and Talking Points for Physical Fitness Counseling in Primary Care}

Assess physical activity at each visit (including type of activity, frequency, intensity, duration)

Link physical fitness with reduced risk of diabetes, hypertension, heart disease, stroke, many cancers, depression/anxiety, premature mortality

Address both aerobic activity and muscle strengthening, which together can be as important as weight loss

WHO physical activity guidelines for adults

Aerobic activity: $\geq 150$ minutes of moderate activity per week (e.g., 30 minutes/day of brisk walking, slow biking) or $\geq 75$

minutes of vigorous activity per week (e.g., 15 minutes/day of jogging/running, fast bicycling, swimming laps)

Muscle strengthening: $\geq 2$ times per week (does not require equipment, but instead may include push-ups, sit-ups, and lunges)

WHO physical activity guidelines for children and youth

Aerobic activity: $\geq 60$ minutes of moderate or vigorous activity per day

Muscle strengthening: $\geq 3$ times per week (e.g., monkey bars and pull-ups)

Prescribe an agreed-upon physical activity tailored to patient's interests, gradually working up to the recommended levels above Encourage record-keeping and provide encouragement or recognize success at each visit

WHO, World Health Organization. 
ers. Universal counseling to promote aerobic fitness and muscle strengthening should be a standard part of the wellness paradigm for all primary care patients.

To see this article online, please go to: http://jabfm.org/content/ 32/1/103.full.

\section{References}

1. Lobelo F, Stoutenberg M, Hutber A. The exercise is medicine global health initiative: a 2014 update. Br J Sports Med 2014;48:1627-33.

2. Joy E. Time for a new 'vital sign'. Providers should monitor patients' physical activity in battle against obesity. Mod Healthc 2013;43:29.

3. Coleman KJ, Ngor E, Reynolds K, et al. Initial validation of an exercise "vital sign" in electronic medical records. Med Sci Sports Exerc 2012;44: 2071-6.

4. Sallis R, Franklin B, Joy L, Ross R, Sabgir D, Stone J. Strategies for promoting physical activity in clinical practice. Prog Cardiovasc Dis 2015;57:375-86.

5. Vuori IM, Lavie CJ, Blair SN. Physical activity promotion in the health care system. Mayo Clin Proc 2013;88:1446-61.

6. Omura JD, Bellissimo MP, Watson KB, Loustalot F, Fulton JE, Carlson SA. Primary care providers' physical activity counseling and referral practices and barriers for cardiovascular disease prevention. Prev Med 2018;108:115-22.

7. Barnes PM, Schoenborn CA. Trends in adults receiving a recommendation for exercise or other physical activity from a physician or other health professional. NCHS Data Brief 2012:1-8.

8. Odulana A, Basco WT, Bishu KG, Egede LE. Dietary and physical activity counseling trends in u.s. children, 2002-2011. Am J Prev Med 2017;53:9-16.

9. Honda K. Factors underlying variation in receipt of physician advice on diet and exercise: applications of the behavioral model of health care utilization. Am J Health Promot 2004;18:370-7.

10. Crump C, Sundquist J, Winkleby MA, Sieh W, Sundquist K. physical fitness among Swedish military conscripts and long-term risk for type 2 diabetes mellitus: a cohort study. Ann Intern Med 2016;164: 577-84.

11. Crump C, Sundquist J, Winkleby MA, Sundquist K. Interactive effects of physical fitness and body mass index on the risk of hypertension. JAMA Intern Med 2016;176:210-6.

12. Crump C, Sundquist J, Winkleby MA, Sundquist K. Interactive effects of obesity and physical fitness on risk of ischemic heart disease. Int J Obes (Lond) 2017;41:255-61.

13. Crump C, Sundquist J, Winkleby MA, Sundquist K. Aerobic fitness, muscular strength and obesity in relation to risk of heart failure. Heart 2017;103: 1780-7.

14. Crump C, Sundquist J, Winkleby MA, Sundquist K. Interactive effects of physical fitness and body mass index on risk of stroke: a national cohort study. Int J Stroke 2016;11:683-94.

15. Crump C, Sundquist J, Winkleby MA, Sundquist K. Interactive effects of aerobic fitness, strength, and obesity on mortality in men. Am J Prev Med 2017; 52:353-61.

16. Crump C, Sundquist J, Winkleby MA, Sundquist K. Height, weight, and aerobic fitness level in relation to the risk of atrial fibrillation. Am J Epidemiol 2018;187:417-26.

17. Lee IM, Shiroma EJ, Lobelo F, et al. Effect of physical inactivity on major non-communicable diseases worldwide: an analysis of burden of disease and life expectancy. Lancet 2012;380:219-29.

18. Oldridge NB. Economic burden of physical inactivity: healthcare costs associated with cardiovascular disease. Eur J Cardiovasc Prev Rehabil 2008;15: 130-9.

19. Warburton DE, Nicol CW, Bredin SS. Health benefits of physical activity: the evidence. CMAJ 2006; 174:801-9.

20. Swift DL, Lavie CJ, Johannsen NM, et al. Physical activity, cardiorespiratory fitness, and exercise training in primary and secondary coronary prevention. Circ J 2013;77:281-92.

21. Borel AL, Nazare JA, Smith J, et al. Visceral and not subcutaneous abdominal adiposity reduction drives the benefits of a 1-year lifestyle modification program. Obesity (Silver Spring) 2012;20:1223-33.

22. Belavy DL, Mohlig M, Pfeiffer AF, Felsenberg D, Armbrecht G. Preferential deposition of visceral adipose tissue occurs due to physical inactivity. Int J Obes (Lond) 2014;38:1478-80.

23. Kim K, Valentine RJ, Shin Y, Gong K. Associations of visceral adiposity and exercise participation with C-reactive protein, insulin resistance, and endothelial dysfunction in Korean healthy adults. Metabolism 2008;57:1181-9.

24. O'Leary VB, Marchetti CM, Krishnan RK, Stetzer BP, Gonzalez F, Kirwan JP. Exercise-induced reversal of insulin resistance in obese elderly is associated with reduced visceral fat. J Appl Physiol (1985) 2006; 100:1584-9.

25. Wu XY, Han LH, Zhang JH, Luo S, Hu JW, Sun K. The influence of physical activity, sedentary behavior on health-related quality of life among the general population of children and adolescents: a systematic review. PLoS One 2017;12:e0187668.

26. Bartsch AL, Harter M, Niedrich J, Brutt AL, Buchholz A. A systematic literature review of self-reported smoking cessation counseling by primary care physicians. PLoS One 2016;11:e0168482.

27. Orrow G, Kinmonth AL, Sanderson S, Sutton S. Effectiveness of physical activity promotion based 
in primary care: systematic review and meta-analysis of randomised controlled trials. BMJ 2012; 344:e1389.

28. Hobbs N, Godfrey A, Lara J, et al. Are behavioral interventions effective in increasing physical activity at 12 to 36 months in adults aged 55 to 70 years? A systematic review and meta-analysis. BMC Med 2013;11:75.

29. Writing Group for the Activity Counseling Trial Research Group. Effects of physical activity counseling in primary care: the Activity Counseling Trial: a randomized controlled trial. JAMA 2001; 286:677-87.

30. Maruthur NM, Wang NY, Appel LJ. Lifestyle interventions reduce coronary heart disease risk: results from the PREMIER Trial. Circulation 2009; 119:2026-31.

31. Albright CL, Cohen S, Gibbons L, et al. Incorporating physical activity advice into primary care: physician-delivered advice within the activity counseling trial. Am J Prev Med 2000;18:225-34.
32. World Health Organization. Global recommendations on physical activity for health. Geneva: World Health Organization; 2010.

33. Baker A. Despite obesity concerns, gym classes are cut. The New York Times. July 10, 2012.

34. Zubala A, MacGillivray S, Frost H, et al. Promotion of physical activity interventions for community dwelling older adults: a systematic review of reviews. PLoS One 2017;12:e0180902.

35. Salvo G, Lashewicz BM, Doyle-Baker PK, McCormack GR. Neighbourhood built environment influences on physical activity among adults: a systematized review of qualitative evidence. Int J Environ Res Public Health. 2018;15:E897.

36. Carlson SA, Fulton JE, Pratt M, Yang Z, Adams EK. Inadequate physical activity and health care expenditures in the United States. Prog Cardiovasc Dis 2015;57:315-23.

37. Artero EG, Lee DC, Lavie CJ, et al. Effects of muscular strength on cardiovascular risk factors and prognosis. J Cardiopulm Rehabil Prev 2012;32:351-8. 